\title{
Race, ethnicity and Indigeneity - challenges and opportunities for embracing diversity in sport
}

\author{
Daryl Adair \\ University of Technology Sydney
}

This issue of the Cosmopolitan Civil Societies Journal was conceived as an outcome of the conference Sport, Race and Ethnicity: Building a Global Understanding, which was staged by the University of Technology Sydney from 30 Nov - 2 Dec 2008. ${ }^{1}$ The event was organised in partnership with the Australian Human Rights Commission (AHRC) and the Department of Immigration and Citizenship, and supported by the School of Leisure, Sport and Tourism, UTS Kuring-gai and the Cosmopolitan Civil Societies Research Centre at UTS. The conference was opened by Graeme Innes (AM), Australian Human Rights Commissioner and Disability Discrimination Commissioner, and the Honourable Laurie Ferguson, Parliamentary Secretary for Multicultural Affairs and Settlement Services. The third day of the symposium featured an AHRC led 'Sport and Cultural Diversity Forum', chaired by Paul Oliver, author of the 2007 report What's the Score? A Survey of Cultural Diversity and Racism in Australian Sport, ${ }^{2}$ and David Peachey, a Wiradjuri man who is best known for his contribution to rugby league football and his commitment to young Aboriginal people through the David Peachey Foundation. ${ }^{3}$ The eighty speakers at the conference included Indigenous peoples from Australia, New Zealand and Canada, together with people of different colour, ancestry and religion from places as diverse as North America, South Africa, the United Kingdom, Brazil and South-East Asia.

The conference was attended by academics, postgraduate students and sport practitioners and the contributors to this issue reflect that diversity. Together their writings emphasise the emergence of sport as a potentially significant contributor to policies and practices of social inclusion and anti-discrimination. Sport, as John Sugden has argued, is neither inherently

\footnotetext{
${ }^{1}$ For details see http://www.business.uts.edu.au/lst/sre/ (accessed 18 August 2010).

${ }^{2}$ For details see http://www.hreoc.gov.au/racial_discrimination/whats the score/index.html (accessed 18 August 2010).

${ }^{3}$ For details see http://davidpeachey.org/ (accessed 18 August 2010). 
'good' nor 'bad' - it was what humans make it to be. ${ }^{4}$ As a social phenomenon, sport is a major part of popular culture and global communication; if managed 'well' it can facilitate understanding of the 'other', mutual respect and a cosmopolitanism ethos. Sport can, of course, promote jingoism, sexism, racism and xenophobia, among other negative attributes. As the papers in this issue of the CCS Journal attest, norms, values, attitudes and power relationships underpin the capacity of sport to either include and engage, or exclude and disengage.

Drew Cottle and Angela Keys' paper 'The "blindside flick”: race issues and Australian rugby league', observes the rise to prominence of Indigenous players in professional rugby league, with a particular focus on their struggles with racism when making a transition from the margins of the sport to its centre stage. Cottle and Keys welcome the rising number of Aboriginal rugby league stars, but deftly point out that Indigenous inclusion does not mean an absence of racism. They also make the very important case that Aboriginal people are not 'natural' athletes, and that belief in them being so can have negative effects in terms of selfbelief in other fields of endeavour. Cottle and Keys conclude by posing a range of provocative questions around rugby league as a multi-faceted site of opportunity, tension, achievement and conflict for Aboriginal people.

Sean Gorman’s paper ‘Sporting chance: Indigenous sport participation in Australian history’, is as critically aware as Cottle's article, but more upbeat in that he believes contemporary sport is more likely to tackle racism than perpetuate it. Drawing on interviews with Indigenous sports stars, such as AFL footballer Michael Long, Gorman argues that without sport providing opportunities - and therefore hopes of achievement - for many young Aboriginal men, they would be in a worse position. This is not just his view but that of Long, who asserts that 'Sport has been our greatest ally' in the fight against racism and in the quest for greater Aboriginal self respect among the Australian community generally. As someone who has worked in Aboriginal Studies for more than two decades, Gorman does not seek to romanticise sport, but he sees in its contemporary form, such as with anti-racism measures in the AFL, the opportunity to build a more inclusive and cohesive community of all comers.

\footnotetext{
4 J. Sugden, 'Critical left-realism and sport interventions in divided societies', International Review for the Sociology of Sport, 45 (3), September 2010, pp.258-272. 
In the article 'Speaking the unspoken: Racism, sport and Māori', H. Raima Hippolite and Toni Bruce continue the theme of Indigenous sport and racism, but their focus is with Māori sportspeople in Aotearoa New Zealand. Hippolite, a Māori postgraduate student, together with Bruce, her Pākehā supervisor, argue that New Zealand sport (and therefore society) is not, as outsiders seem to perceive it, a haven for positive relations between ethnic and racial groups. That perception is sustained, the authors argue, by a pervasive culture of silence in and around New Zealand sport. If there is no discussion among sport stakeholders about discrimination on the basis of colour, culture or ancestry then it is presumed not to exist. However, Hippolite's interviews with Māori sportspeople reveal a more complex picture: although Indigenous athletes are eligible to take part in any sport, their inclusion can be compromised, such as by a lack of awareness among Pākehā about Māori cultural needs and their overarching responsibilities to family and kin, all of which need to be balanced into sporting commitments. The authors therefore recommend dialogue and consultation between ethnocultural groups and, above all, they cry out for open conversation in respect of racism, exclusion and marginalisation in New Zealand sport. This article is also noteworthy in the context of Hippolite negotiating her way, as both a Maori researcher and university student, through the norms and conventions of academic scholarship. She describes a complex and difficult journey, replete with conflicts and compromises - from which this paper is an important and most welcome outcome.

Megan Stronach and Daryl Adair extend the discussion of Indigeneity in sport, but this time in the context of Australian Aboriginal people and around the profession of boxing. Stronach's ongoing Doctoral research examines the retirement experiences of Indigenous athletes in the AFL, the NRL and boxing, wherein Aboriginal and Torres Strait Islander people have been particularly prominent in recent decades. In this paper, Stronach and Adair note that Aboriginal fighters are sought by talent scouts and welcomed by boxing organisations, but much less thought, and indeed enthusiasm, has been directed towards their transition, upon retirement, into a career beyond the ring. Stronach's interviews with boxers revealed that they were, in Pierre Bourdieu's theoretical terms, replete with physical capital, but that they typically relied on this to the exclusion of non-physical attributes, such as education or vocational training. Stronach and Adair have conceived an addition to Bourdieu's theoretical repertoire - the notion of future capital. This refers to a bank of skills and connections, such as by undertaking technical or university training, that provides no 
immediate capital benefit, but instead facilitates the mobility to earn capital in the future. The authors see this as both a pathway and process towards boxers having greater choice of employment and career once their time as a boxer has ended. This seems particularly important for Indigenous prize fighters, argue Stronach and Adair, because the vast majority of them only envisage a role in boxing - whether as a coach or personal trainer - once their days inside the ring are over. The post-retirement transition is difficult for any professional athlete; this article demonstrates that it is particularly challenging for Aboriginal boxers.

Stan Thangaraj’s paper, “"Liting it up”: Popular culture, Indo-Pak basketball, and South Asian American institutions', provides ethnographic insights into migration, ethnicity and race in sport. Indian and Pakistani communities, while typically having different religious and ancestral loyalties, have a shared history since the partition of the sub-continent and, in the context of America, a common perception that they are similar through being 'Asian'. In the homelands, sports like cricket and hockey provide important cultural connections between the peoples of India and Pakistan, but in the US - where games of the former British Empire have no currency - there are few opportunities (and indeed little sport-appropriate space) to undertake such activities. Intriguingly, Thangaraj notes that Indo-Pak community elders in the US instead actively encouraged young men to take up basketball on grounds beside temples, churches or mosques. This allowed the boys to maintain their religious obligations, but also engage in a mainstream 'American' physical activity. A link with tradition and modernity proved popular, with Thangaraj evaluating thriving Indo-Pak basketball competitions in both Atlanta and Chicago. Thangaraj soon discovered, however, that this engagement with the modern and mainstream was constrained by the customary values and traditions of Indo-Pak communities. He concluded that basketball, for these groups, is malecentred - with virtually no active role for females. Furthermore, the basketball spaces were not only male dominated, they were heterosexist; gay men were simply not welcome. Thangaraj's case study is a telling example of how ethnocultural sporting environments can be liberating for some but disempowering to others.

The final paper in this volume, a collaboration by Anne Bunde-Birouste, Nicholas Bull and Brad McCarroll, provides analysis of an ambitious grassroots sport program conducted with the aid of a range of partners - a university, a sport consultant, volunteers and corporate sponsors. 'Football United' is a development program that uses the sport of soccer to foster 
social cohesion in areas of the Sydney community with high levels of refugee settlement. It does this by engaging young refugees and their friends in sport, and, via a football-specific cultural framework, instilling in them leadership, skills development, mentoring, and the creation of social capital by connecting them, as Football United members, to a range of local community leaders and social organisations. The purpose of the paper presented in this volume is to analyse the relationship of Football United, a not-for-profit program, with a key commercial sponsor - JP Morgan. In an era of corporate social responsibility, it has become customary for companies to donate funds to charitable and virtuous social ventures, but often there is little connection between the donor and the recipient organisation other than an exchange of funds and good wishes. In the case of JP Morgan there was a genuine effort on the part of the company to provide in-kind support over and above financial assistance. However, as the article indicates, there were logistical constraints around the extent to which corporate professionals could actively engage in Football United programs. The authors conclude that a successful relationship between sponsor and sponsee relies on effective communication and a clear articulation of the needs and expectations of both parties. 